Gut, 1989, 30, 835-838

\title{
Enhanced production of interleukin 1- $\beta$ by mononuclear cells isolated from mucosa with active ulcerative colitis of Crohn's disease
}

\author{
Y R MAHIDA, K WU, AND D P JEWELL \\ From the Gastroenterology Unit, Radcliffe Infirmary, Oxford
}

SUMMARY IL1- $\beta$ production by mononuclear cells isolated from normal and active inflammatory bowel disease mucosa was studied. Significantly more IL1- $\beta$ was produced spontaneously by mononuclear cells from the inflamed mucosa compared with those from normal colonic mucosa (median $190 \mathrm{pg} / \mathrm{ml}$ (range 45-700) $v 20 \mathrm{pg} / \mathrm{ml}(0-165)$ ). Stimulation with lipopolysaccharide enhanced IL1- $\beta$ production by mononuclear cells from active inflammatory bowel disease mucosa but not those from normal mucosa. Depleting the mononuclear cells of macrophages, by panning with monoclonal antibody $3 \mathrm{C10}$, reduced the amount of IL1- $\beta$ produced. Enhanced IL1- $\beta$ production from the inflamed mucosa may play an important role in the mediation of many inflammatory responses. The enhanced production appears to be the result of a recruited population of cells.

Interleukin 1 (IL1) is a polypeptide produced predominantly by stimulated macrophages and monocytes. The structurally distinct forms of IL1, IL1- $\alpha$ and IL1- $\beta$ have been identified. They are coded by two separate genes on chromosome 2 and messenger RNA for IL1- $\beta$ predominates over that coding for IL1- $\alpha{ }^{1}$ Although they share only $26 \%$ sequence homology, their biological activities are, for the most part, identical. ${ }^{2}$ This could be explained by identical cell surface receptors for the two forms of IL1. ${ }^{3}$ Interleukin 1 exerts an influence over a wide range of biological functions. It acts as an endogenous pyrogen and induces hepatocytes to synthesise acute phase proteins - for example, serum amyloid A, C-reactive protein, fibrinogen. ${ }^{12+}$ It activates $\mathrm{T}$ lymphocytes, ${ }^{5}$ increases antibody synthesis by $B$ cells ${ }^{6}$ and induces granulocyte release from the bone marrow.' It enhances fibroblast collagen production $^{8}$ and alters prostaglandin production. ${ }^{1}$ Thus IL1 appears to play a major role in inflammatory responses.

There is little current information on IL-1 production by the intestinal mucosa in ulcerative colitis or Crohn's disease. The aim of this study was to

Address for correspondence: Dr D P Jewell, Gastroenterology Unit, Radcliffe Infirmary, Oxford OX2 6HE.

Accepted for publication 7 November 1988 investigate IL1- $\beta$ production by mononuclear cells isolated from normal and inflamed mucosa (with or without stimulation with lipopolysaccharide (LPS) using ELISA.

\section{Methods}

\section{TISSUE}

Normal colonic mucosa was obtained from colon resected for carcinoma (six) or for severe idiopathic constipation (one). The mucosa used was macroscopically and histologically normal and that from colon resected from carcinoma was obtained at least $5 \mathrm{~cm}$ from the tumour.

Inflamed colonic and ileal mucosa was obtained from intestine resected for active inflammatory bowel disease. Nine patients had ulcerative colitis, two Crohn's colitis and five ileal Crohn's disease. All the patients were on intravenous corticosteroids at the time of the operation.

ISOLATION AND CULTURE OF INTESTINAL

MONONUCLEAR CELLS

Mononuclear cells (MNC) were isolated from normal and inflamed mucosa using a modified EDTAcollagenase technique. ${ }^{9}$ In brief, epithelial cells were removed by shaking strips of mucosa with $5 \mathrm{mmol}$ 
EDTA in three, half hour steps. After washing, the mucosa was digested with collagenase (from Clostridium histolyticum) at a concentration of $1 \mathrm{mg}$ / $\mathrm{ml}$ in $10 \%$ fetal calf serum/RPM1 (Gibco), for three hours at $37^{\circ} \mathrm{C}$. Mononuclear cells were obtained by centrifugation on Ficoll-Paque (Pharmacia).

In some studies, the mononuclear cells were depleted of macrophages by a panning technique ${ }^{10}$ using a macrophage specific monoclonal antibody $3 \mathrm{C}^{11} 0^{11}$ (gift from Dr Steinman, New York).

Cytospin preparations of unfractionated and $3 \mathrm{C} 10$ depleted mononuclear cells were made and stained with monoclonal antibodies Y1/82A (macrophage specific, obtained from Dr D Y Mason, Oxford), TO15 (B cell specific, obtained from Dr D Y Mason, Oxford), and T910 (T cell specific; Dakopatts). For Y1/82A, the peroxidase technique ${ }^{12}$ was used for staining and for the other antibodies, the alkaline phosphatase anti-alkaline phosphatase (APAAP) technique ${ }^{13}$ was used.

\section{CELL CULTURE}

Cultures were done in flat bottom, tissue culture multiwell plates (Flow laboratories). Intestinal mononuclear cells were cultured at a concentration of $1 \times 10 \% \mathrm{ml}$ in $10 \%$ fetal calf serum/RPM 1 , in the presence or absence of lipopolysaccharide (LPS; 10 $\mu \mathrm{g} / \mathrm{ml}$; Sigma) for 45 hours. Culture supernant was collected by centrifugation at $600 \mathrm{~g}$ for 10 minutes followed by filtration with a $0 \cdot 2 \mu$ filter. The supernatant was stored at $-70^{\circ} \mathrm{C}$ before analysis.

Peripheral blood mononuclear cells (isolated by

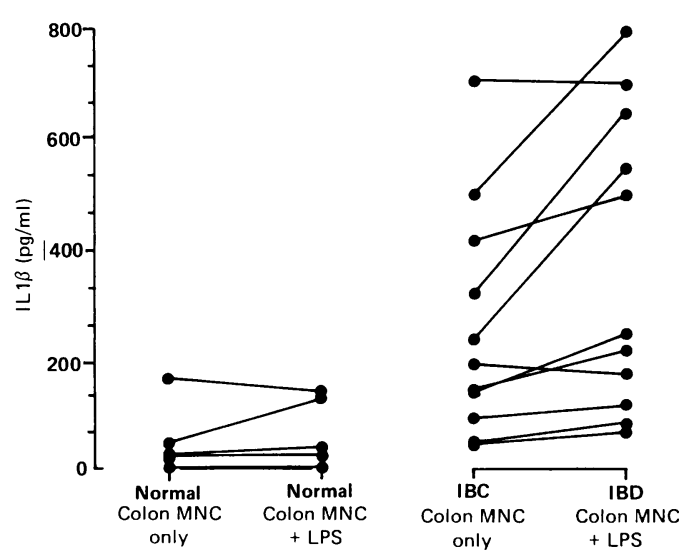

Fig. 1 ILI- $\beta$ production by MNC isolated from normal (seven) and inflamed (11) colonic mucosa, either spontaneously or in the presence of LPS. Normal colonic $M N C$ only $\vee I B D$ colonic $M N C$ only: $p<0 \cdot 01$; normal colonic MNC + LPS $\vee I B D$ colonic $M N C+L P S: p<0 \cdot 01$; normal colonic MNC only v normal colonic MNC+LPS: p-NS; IBD colonic MNC only $\vee I B D$ colonic $M N C+L P S$ : $p<0 \cdot 01$. centrifugation on Ficoll-Paque) from three healthy individuals were also studied as described above.

\section{MEASUREMENT OF IL $1-\beta$}

The amount of IL1- $\beta$ present in the supernatants was measured using ELISA (Cistron Biotechnology). It consisted of microtitration wells coated with monoclonal antibody specific for IL1- $\beta$ (solid phase). Polyclonal rabbit anti-IL1- $\beta$ was used to detect IL1- $\beta$ bound to the solid phase. Horseradish peroxidase conjugated anti-rabbit-IgG was then added to the test wells. After development of the substrate, the colour intensity was measured using a microtitration plate reader. The tests were performed in duplicate and the amount of IL1- $\beta$ in each sample was derived from the optical density curve of known standards. Previous studies ${ }^{14}$ have shown the specificity of this assay for IL1- $\beta$, with no cross-reactivity with tumour necrosis factor- $\alpha$, interleukin 2 or interferon-gamma. The sensitivity of this assay has been shown to be equivalent or better than available bioassays. ${ }^{14}$ Reproducibility was within $10 \%$.

STATISTICAL ANALYSIS

Statistical analysis was performed using the Wilcoxon's rank-sum test for non-parametric data, paired or unpaired. As data were not normally distributed, results are expressed as a median and range.

\section{Results}

There was no significant difference in the proportion of macrophages in mononuclear cells isolated from normal and inflamed colonic mucosa. This was shown by staining cytospin preparations of MNC with the macrophage specific monoclonal antibody Y1/82A. Mononuclear cells from normal colonic mucosa contained median $13 \%$ (range 9-19) of macrophages and cells from inflamed colonic mucosa, median $14.5 \%$ (range $8-22$ ).

Preliminary studies showed that the amount of

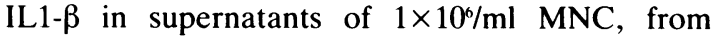
inflamed mucosa, was usually in the range detected by the assay.

Figure 1 shows the amount of IL1- $\beta$ produced by MNC isolated from inflamed inflammatory bowel disease mucosa and from normal mucosa, with and without stimulation with LPS. There was significantly more IL1- $\beta$ produced by MNC isolated from ulcerative colitis or Crohn's colitis mucosa, compared with MNC from normal mucosa (median $190 \mathrm{pg} / \mathrm{ml}$ (range $45-700)$ and $20 \mathrm{pg} / \mathrm{ml}(0-165)$ respectively). Lipopolysaccharide stimulation enhanced IL1- $\beta$ production by $\mathrm{MNC}$ from inflammatory bowel disease colons but not from normal colons (Fig. 1). 

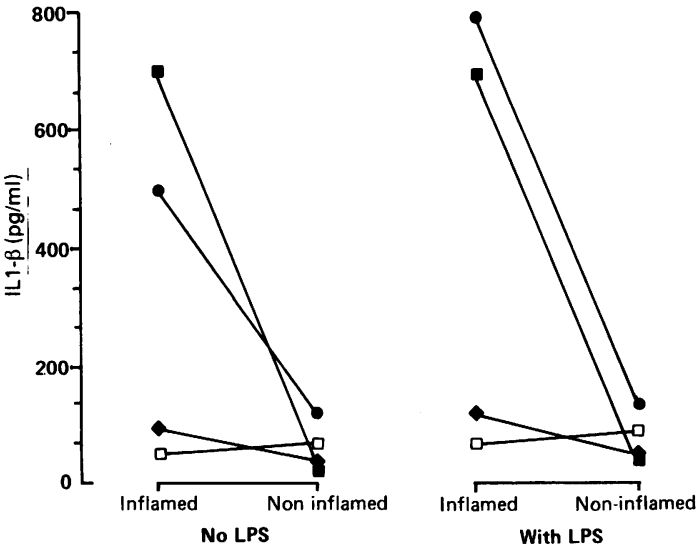

Fig. 2 ILI- $\beta$ production by $M N C$ (in the presence or absence of LPS) from inflamed and non-inflamed mucosa of four colons with distal ulcerative colitis.

Mononuclear cells isolated from five specimens with ileal Crohn's disease also produced high levels of IL1- $\beta$ (spontaneously - median $220 \mathrm{pg} / \mathrm{ml}$ (range 100-370); after stimulation with LPS - median 235 $\mathrm{pg} / \mathrm{ml}$ (range 150-470)).

In four colons resected for ulcerative colitis (with distal inflammation) it was possible to study MNC isolated from inflamed as well as non, or, minimallyinflamed areas of the same colon. In three out of four, more IL1- $\beta$ was produced by mononuclear cells from inflamed areas compared with those from non, or, minimally-inflamed areas (Fig. 2).

Efficacy of the LPS used in these studies was confirmed in experiments on peripheral blood MNC from three healthy individuals. Mononuclear cells

Table 1 Interleukin 1- $\beta(\mathrm{pg} / \mathrm{ml})$ in supernatant of $10^{\natural} / \mathrm{ml}$ of unfractionated $M N C$ and $M N C$ depleted of macrophages with antibody $3 \mathrm{C} 10$, isolated from three colons with active ulcerative colitis

\begin{tabular}{llc}
\hline & Unfractionated MNC & 3 C10 depleted $M N C$ \\
\hline$(1)$ & 85 & 25 \\
$(2)$ & 95 & 0 \\
$(3)$ & 320 & 80 \\
\hline
\end{tabular}

Table 2 Median (range) percentage of macrophages, $T$ cells and $B$ cells (identified by monoclonal antibodies) in cytospin preparations of unfractionated MNC and MNC after panning with antibody $3 \mathrm{C} 10$. The $M N C$ were isolated from mucosa of three colons with active ulcerative colitis

\begin{tabular}{|c|c|c|c|}
\hline & Macrophages & $T$ cells & B cells \\
\hline Unfractionated MNC & $18(15-23)$ & $44(40-48)$ & $16(10-18)$ \\
\hline 3C10 depleted MNC & $5(4-7)$ & $41(40-46)$ & $17(10-23)$ \\
\hline
\end{tabular}

$\left(1 \times 10^{\circ} / \mathrm{ml}\right.$; cultured under the same conditions as intestinal MNC) cultured without LPS produced median $85 \mathrm{pg} / \mathrm{ml}$ (range $60-130$ ) of IL1- $\beta$ but in the presence of LPS $(10 \mu \mathrm{g} / \mathrm{ml})$ produced median 2280 $\mathrm{pg} / \mathrm{ml}$ (range 1840-3100) of the cytokine.

Interleukin $1-\beta$ production by unfractionated MNC and MNC depleted of macrophages by panning with monoclonal antibody $3 \mathrm{C} 10$, was also compared (Table 1). In all three colons, there was less IL1- $\beta$ in supernatants of mononuclear cells depleted of macrophages. Depletion of macrophages by panning was confirmed by staining cytospin preparations of the mononuclear cells with macrophage specific monoclonal antibody Y1/82A (Table 2).

\section{Discussion}

This study shows that mononuclear cells isolated from mucosa of colons with active inflammatory bowel disease, cultured in vitro, produced much greater amounts of IL1- $\beta$ than mononuclear cells isolated from normal colonic mucosa. This increase appears to be the result of enhanced production of the cytokine on a per cell basis as there was no significant difference in the proportion of macrophages present in MNC from normal or inflamed colonic mucosa. Stimulation with LPS enhanced production of this cytokine by mononuclear cells isolated from inflamed mucosa but not by those cells isolated from normal colonic mucosa.

Although other cells have been shown to produce IL1, macrophages are likely to be the major source of this cytokine. ' This was confirmed in our experiments where IL1- $\beta$ production was considerably reduced after depletion of macrophages by panning with the monoclonal antibody $3 \mathrm{C} 10$.

Enhanced production of IL1- $\beta$ by cells isolated from inflamed colons is likely to be caused by the presence of activated macrophages. ${ }^{15}$ Peripheral blood monocytes stimulated with endotoxin or phagocytosis produce IL1. The lack of such a response to LPS by mononuclear cells isolated from normal colons suggests that normal intestinal macrophages are 'desensitised' to LPS with respect to this function. Thus the activated macrophages which produce IL1- $\beta$ in the mucosa of inflammatory bowel disease are likely to be derived from circulating monocytes (an elicited population of cells). Potency of the LPS used in these studies was confirmed by experiments on peripheral blood MNC. Increased monocyte turnover has been shown in inflammatory bowel disease. ${ }^{16}$ They have also been shown to be activated. ${ }^{718}$ Using mouse thymocyte proliferation assay, spontaneous IL1 production by peripheral blood mononuclear cells in patients with Crohn's disease has been reported. ${ }^{19}$ 
The normal intestinal macrophage is located predominantly below the epithelium and is likely to come in contact with a wide variety of antigens and bacterial products. Thus its inability to be stimulated by LPS may protect against an inflammatory response being mounted unnecessarily under normal circumstances. It is likely that during an inflammatory response, monocytes are recruited into the mucosa. These may then mediate responses like the production of IL1 and generation of oxygen radicals, triggers for the development of an even greater inflammatory response.

All the patients with inflammatory bowel studied were receiving corticosteroids. It is unlikely that the enhanced production of IL1- $\beta$ is due to the effect of this drug. On the contrary, corticosteroids have been shown to inhibit the production of this cytokine..$^{20}$ Therefore, this drug may actually be diminishing the production of IL1- $\beta$ by MNC from inflamed mucosa.

In addition to being an important mediator of inflammatory and immunological reactions, ${ }^{121}$ in inflammatory bowel disease, IL1 is likely to be involved in the repair of damaged connective tissue by synthesising and remodelling components of the matrix like collagen, fibronectin, and proteoglycans ${ }^{82}$ and may contribute to fibrosis. It may also be involved in the induction of mucus secretion. ${ }^{22}$

Dr Mahida was supported by the Medical Research Council. We are grateful to $\mathrm{Mr}$ Kettlewell and $\mathrm{Mr}$ Mortensen for the operation resection specimens.

\section{References}

1 Dinarello CA. Biology of interleukin 1. Faseb J 1988; 2: 108-15.

2 Enders S, Van Der Meer JWM, Dinarello CA. Interleukin 1 and the pathogenesis of fever. Eur J Clin Invest 1987; 17: 469-74.

3 Dower SK, Kronheim SR, Hopp HP, et al. The cell surface receptors for interleukin 1- $\alpha$ and interleukin $1-\beta$ are identical. Nature 1986; 324: 266-8.

4 Dinarello CA. Interleukin 1 and the pathogenesis of the acute-phase response. $N$ Engl J Med 1984; 311: 1413-8.

5 Mizel SB. Interleukin 1 and $\mathrm{T}$ cell activation. Immunol Rev 1982; 63: 51-72.

6 Falkoff RJM, Muraguchi A, Hong J-X, Butler JL, Dinarello CA, Fauci AS. The effects of interleukin 1 in human B cell activation and proliferation. J Immunol 1983; 131: 801-5.

7 Kampschmidt RF. Leucocytic endogenous mediator/ endogenous pyrogen. In: Powanda MC, Canomico PG, eds. The physiologic and metabolic responses of the host to infection and inflammation. Amsterdam: Elsevier/ North Holland, 1981: 55-74.
8 Schmidt JA, Mizel SB, Cohen D, Green I. Interleukin 1, a potential regulator of fibroblast proliferation. J Immunol 1982; 128: 2177-82.

9 Bull DM, Bookman MA. Isolation and functional characterization of human intestinal mucosal lymphoid cells. J Clin Invest 1977; 59: 966-74.

10 Wysocki LT, Sato VL. 'Panning' for lymphocytes: a method for cell selection. Proc Natl Acad Sci USA 1978; 75: 2844-8.

11 Van Voorhis WC, Steinman RM, Hair LS, et al. Specific antimononuclear phagocyte monoclonal antibodies. Application to the purification of dendritic cells and tissue localization of macrophages. J Exp Med 1983; 58: $126-45$.

12 Gatter KC, Falini B, Mason DY. The use of monoclonal antibodies in histopathological diagnosis. In: Anthony PP, MacSween NM, eds. Recent advances in histopathology. Vol 12. Edinburgh: Churchill Livingstone, 1984: 135-67.

13 Cordell JL, Falini B, Erber WN, et al. Immunoenzymatic labelling of monoclonal antibodies using immune complexes of alkaline phosphatase and monoclonal anti-alkaline phosphatase (APAAP complexes). J Histochem Cytochem 1984; 32: 219-29.

14 Gaffney EW, Chu C-W, Lingenfelter SE, Lisi PJ, Koch GA. Enzyme linked immunoassay with monoclonal antibody for human interleukin-1. Biotechniques 1987; 5: 652-6.

15 Besedovsky H, Rey AD, Sorkin E, Dinarello CA. Immunoregulatory feedback between interleukin 1 and glucocorticoid hormones. Science 1986; 233: 652-4.

16 Meuret G, Bitzi A, Hammer B. Macrophage turnover in Crohn's disease and ulcerative colitis. Gastroenterology 1978; 74: 501-3.

17 Mee AS, Szawatakowski M, Jewell DP. Monocytes in inflammatory bowel disease: phagocytosis and intracellular killing. J Clin Pathol 1980; 33: 921-5.

18 Doe WF, Forsman B. Chronic inflammatory bowel disease: increased plasminogen activator secretion by mononuclear phagocytes. Clin Exp Immunol 1982; 48: $256-60$.

19 Satsangi J, Wolstencroft RA, Cason J, Ainley CC, Dumonde DC, Thompson RPH. Interleukin 1 in Crohn's disease. Clin Exp Immunol 1987; 67: 594-605.

20 Kern JA, Lamb RJ, Reed JC, Daniele RP, Nowell PC. Dexamethazone inhibition of interleukin 1 Beta production by human monocytes. Post-transcriptional mechanisms. J Clin Invest 1988; 81: 237-44.

21 Maury CPJ. Interleukin 1 and the pathogenesis of inflammatory diseases. Acta Med Scand 1986; 220: 291-4.

22 Han V, Resau J, Prendergast R, Scott A, Levy DA. Interleukin 1 induces mucus secretion from mouse intestinal explants. Int Arch Allergy Appl Immunol 1987; 82: 364-65.

23 Postlethwaite AE, Lachman LB, Mainardi CL, Kang AH. Interleukin 1 stimulation of collagenase production by cultured fibroblasts. $J$ Exp Med 1983; 157: 801-6. 